\title{
PENYULUHAN PEMANFAATAN CATU DAYA LISTRIK MANDIRI DI DESA GILI GEDE INDAH KABUPATEN LOMBOK BARAT
}

\section{UTILIZATION OF SELF POWERING ELECTRIC SUPPLY IN GILI GEDE INDAH VILLAGE, LOMBOK BARAT DISTRICT}

\author{
Ida Bagus Fery Citarsa*, I Nyoman Wahyu Satiawan, Supriono, Cipta Ramadhani \\ Program Studi Teknik Elektro, Universitas Mataram \\ Jalan Majapahit, Nomor 62, Kota Mataram, Provinsi NTB, 83115 \\ ${ }^{*}$ Alamat korespondensi : ferycitarsa@unram.ac.id
}

(Tanggal Submission: 27 Januari 2020, Tanggal Accepted: 16 April 2020 )

\begin{abstract}
ABSTRAK
Salah satu daerah di Kabupaten Lombok Barat yang belum teraliri listrik dari PLN adalah Pulau Gili Gede. Masyarakat di sana masih menghadapi beberapa kendala dalam penyediaan kebutuhan primer, seperti ketersediaan air bersih, keterbatasan tenaga listrik dan masalah telekomunikasi. Saat ini untuk ketersediaan kebutuhan tenaga listrik dipenuhi dengan mengandalkan genset dengan kapasitas sangat terbatas yang dibiayai dari iuran warga. Kegiatan pengabdian kepada masyarakat ini bertujuan untuk mengatasi persoalan yang dihadapi oleh masyarakat di Desa Gili Gede Indah, berkaitan dengan masalah ketersediaan tenaga listrik, diusulkan pembuatan suatu catu daya listrik mandiri. Hal ini dilakukan dengan metode penyuluhan mengenai prinsip kerja dan penggunaan catu daya listrik mandiri kepada masyarakat di Desa Gili Gede Indah. Pada waktu yang telah disepakati, tim pelaksana yang beranggotakan staf pengajar Jurusan Teknik Elektro Fakultas Teknik Universitas Mataram telah melaksanakan kegiatan pengabdian kepada masyarakat di Desa Gili Gede Indah dengan memberikan penyuluhan cara penggunaan sekaligus serah terima catu daya mandiri bertenaga batere sehingga mitra pelaksana dapat memahami prinsip kerja dan cara penggunaan kedua macam peralatan tersebut di atas dengan baik. Dengan menggunakan catu daya mandiri bertenaga batere ini dapat menunjang kegiatan masyarakat yang membutuhkan layanan tenaga listrik sehingga dapat meningkatkan kinerja dan produktivitas mereka.
\end{abstract}

Kata kunci : Gili Gede Indah, catu daya listrik mandiri, batere

\section{PENDAHULUAN}

Salah satu daerah di Kabupaten Lombok Barat yang belum teraliri listrik dari PLN adalah Pulau Gili Gede. Pulau Gili Gede berada pada posisi koordinat geografis $8^{\circ} 44^{\prime} 18.016$ "Lintang Selatan $115^{\circ} 53^{\prime} 12.041^{\prime \prime}$ Bujur Timur, dengan luas pulau \pm $317 \mathrm{Ha}$. Pulau Gili Gede adalah pulau terbesar yang dimiliki Kabupaten Lombok Barat. Batas wilayah Pulau Gili Gede pada bagian sebelah utara berbatasan dengan Selat Lombok, di bagian selatan berbatasan dengan Laut Desa Pelangan, di barat berbatasan dengan Laut Desa Batu Putih dan untuk bagian timur berbatasan dengan Laut Desa Sakoteng Barat.

Di Pulau ini terdapat 5 dusun, yaitu Dusun Gendang Siang, Dusun Labuan Cenit, Dusun Orong Bukang, Dusun Tanjungan dan Dusun Gili Gede. Pulau Gili Gede masuk dalam status kawasan Desa Kepulauan, untuk status kepemilikan pulau adalah milik hak ulayat atau adat, hanya saja ada sekitar 4 titik wilayah pulau yang dimiliki oleh pihak swasta 
juga asing yang dijadikan resort. Tetapi ini menguntungkan warga karena beberapa warga yang menjadi pegawai resort tersebut. Secara administrasi Pulau Gili Gede terletak di Desa Gili Gede Indah, Kecamatan Sekotong Tengah, Kabupaten Lombok Barat, Propinsi Nusa Tenggara Barat. Jumlah penduduk Pulau Gili Gede 1380 jiwa dari \pm 438 kepala keluarga dengan persentase perempuan lebih banyak. Untuk mata pencaharian penduduk lebih banyak sebagai nelayan tangkap sekitar $80 \%$ dan nelayan budidaya 20\%. Ada terdapat 5 kelompok nelayan di Pulau Gili Gede. (Direktorat Pendayagunaan Pulau-pulau Kecil, 2012)

Masyarakat di sana masih menghadapi beberapa kendala dalam penyediaan kebutuhan primer, seperti ketersediaan air bersih, keterbatasan tenaga listrik dan masalah telekomunikasi. Saat ini untuk ketersediaan kebutuhan tenaga listrik dipenuhi dengan mengandalkan genset dengan kapasitas sangat terbatas yang dibiayai dari iuran warga. Genset ini digunakan untuk melayani kebutuhan listrik masyarakat hanya dari jam 18.00 - 24.00 WITA dan hanya mampu mencatu beban kurang lebih 100 Watt per rumah tangga. Sementara pada pagi hari sampai sore hari masyarakat tidak dapat menikmati layanan tenaga listrik. Hal ini tentunya akan menjadi persoalan bagi masyarakat apabila mereka membutuhkan layanan tenaga listrik pada saat pagi sampai sore hari, misalnya: untuk mengisi batere handphone, menyalakan peralatan elektronik (televisi, radio) untuk kebutuhan aksesibilitas informasi, kegiatan administrasi desa atau kegiatan sosial masyarakat desa lainnya.

Untuk mengatasi persoalan yang dihadapi oleh masyarakat di Desa Gili Gede Indah, berkaitan dengan masalah ketersediaan tenaga listrik, diusulkan pembuatan suatu catu daya listrik mandiri (Luo, 2013). Catu daya ini terdiri dari batere, serta alat konversi daya listrik DC - AC (inverter) yang nantinya dapat dipergunakan untuk merubah sumber daya DC (baterai/aki) tegangan rendah 12- $24 \mathrm{~V}$ menjadi sumber daya $\mathrm{AC}$ tegangan $220 \mathrm{~V}$. Aki/baterai dapat diisi (charge) dengan menggunakan sebagian kecil daya disuplai oleh genset pada saat malam hari (dari jam 18.00 24.00 WITA) untuk selanjutnya dapat digunakan pada pagi sampai dengan sore hari.

Salah satu bagian dari dari catu daya mandiri ini yaitu inverter merupakan salah satu focus bidang penelitian dari anggota pelaksana pengabdian pada masyarakat ini yang tergabung dalam kelompok riset Power Electronics and Motor Drives Research Group (Kelompok Riset Elektronika Daya dan Kendali Motor Listrik). Satiawan, dkk, (2015, 2017) serta Citarsa, dkk (2016) telah mengembangkan pembuatan inverter multilevel Cascaded $\mathrm{H}$-Bridge ( $\mathrm{CHB}$ ) satu fasa menggunakan teknik modulasi carrier-based PWM, yaitu teknik modulasi multicarrier phase-shifted dan levelshifted, dimana sinyal pulsa dibangkitkan menggunakan Arduino Mega 2560.

\section{METODE KEGIATAN}

Kegiatan pengabdian kepada masyarakat ini dilaksanakan melalui 3 tahapan, yaitu tahap persiapan, tahap pelaksanaan, dan tahap evaluasi.

\section{Tahap persiapan}

1. Survey awal kebutuhan tenaga listrik dari mitra.

2. Perhitungan kapasitas catu daya listrik mandiri untuk menyesuaikan dengan kebutuhan tenaga listrik dari mitra.

3. Perancangan catu daya listrik mandiri.

4. Perhitungan jenis dan banyak alat dan bahan yang diperlukan untuk pembuatan catu daya listrik mandiri.

\section{Tahap pelaksanaan}

1. Pembelian alat dan bahan yang diperlukan untuk pembuatan catu daya listrik mandiri.

2. Perakitan catu daya listrik mandiri.

3. Pengujian catu daya listrik mandiri

4. Pemasangan disertai peragaan cara penggunaan catu daya listrik mandiri pada lokasi mitra.

\section{Tahap evaluasi}

1. Kunjungan lapangan untuk mengetahui hasil penggunaan catu daya listrik mandiri pada mitra untuk mengetahui kelebihan atau kekurangan yang mungkin masih dimiliki untuk perbaikan ke depan.

2. Pembuatan laporan kegiatan pengabdian pada masyarakat ini. 


\section{HASIL DAN PEMBAHASAN}

\section{Tahap Persiapan}

Sesuai dengan metodologi yang direncanakan, kegiatan pengabdian masyarakat ini dimulai dengan melakukan tahap persiapan. Tahap ini dimulai dengan mengunjungi mitra untuk melakukan survey awal kebutuhan tenaga listrik dari mitra. Berdasarkan observasi dan wawancara yang dilakukan oleh tim pelaksana, diperoleh informasi bahwa umumnya kebutuhan daya listrik untuk rumah tangga pada pagi sampai dengan siang/sore hari tidak terpenuhi karena genset sebagai sumber daya listrik utama di desa ini hanya dinyalakan pada sore sampai dengan tengah malam, dari jam 18.00 sampai 24.00 wita. Kebutuhan tenaga listrik pada siang hari antara lain untuk mensuplai:

1. Mencharge hp.

2. Menyalakan laptop (kantor desa).

3. Menyalakan televisi pada acara-acara penting/menarik, seperti: berita, siaran langsung sepak bola, dll.

\section{Tahap pelaksanaan}

Kegiatan tahap selanjutnya adalah tahap pelaksanaan yang dimulai dengan pembelian bahan-bahan yang diperlukan untuk pembuatan catu daya listrik mandiri. Berdasarkan survey pembelian peralatan yang dilakukan oleh tim pelaksana baik melalui internet maupun di penjual langsung seputaran kota Mataram, diperoleh informasi untuk bahan-bahan catu daya listrik mandiri dapat dibeli baik melalui toko online (internet) maupun offline.

\section{Tabel 1. Bahan pembuatan catu daya mandiri}

\begin{tabular}{clcc}
\hline No. & Nama Bahan & Jumlah & Satuan \\
\hline 1. & Baterai 12 V 7 Ah & 1 & Buah \\
2. & Pendingin (Heat Sink) & 1 & Buah \\
3. & Acrylic 1 m2 & 1 & Buah \\
4. & Power Mosfet + IC & 1 & Set \\
5. & Trafo CT 2 A & 1 & Buah \\
6. & Besi siku + baut & 1 & Set \\
7. & Box aki + box trafo & 1 & Set \\
\hline
\end{tabular}

Setelah semua bahan lengkap maka tahap selanjutnya adalah pembuatan catu daya mandiri dengan tahapan:
1. Perancangan rangkaian elektronika inverter, alat charger baterai dan baterai.

2. Pembuatan rangkaian elektronika inverter, alat charger baterai dan baterai.

3. Pembuatan inverter.

4. Pembuatan alat charger baterai

5. Pembuatan box wadah rangkaian inverter, alat charger baterai dan baterai menggunakan besi, akrilik, baut.

6. Memasukkan rangkaian inverter, alat charger baterai dan baterai ke dalam box.

7. Pembuatan terminal-terminal pada box wadah rangkaian inverter, alat charger baterai dan baterai.

8. Uji coba peralatan catu daya mandiri.

9. Pengukuran nilai-nilai dihasilkan catu daya mandiri.

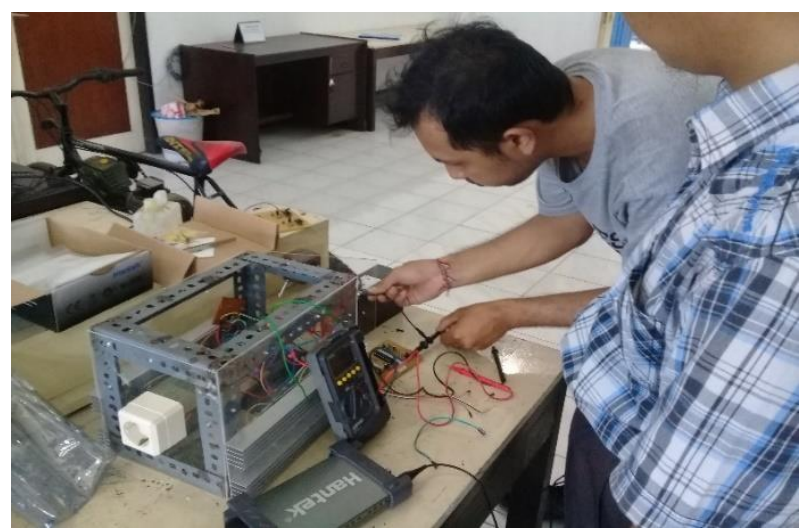

Gambar 1. Uji coba dan pengukuran nilai-nilai keluaran catu daya listrik mandiri.

Setelah dilakukan pembuatan catu daya listrik mandiri kegiatan selanjutnya adalah tim pelaksana memberi penyuluhan mengenai prinsip kerja catu daya mandiri bertenaga batere kepada warga Desa Gili Gede Indah sebagai mitra pelaksana. Dilanjutkan dengan tanya jawab dengan mitra pelaksana mengenai prinsip kerja peralatan yang dibawa. 


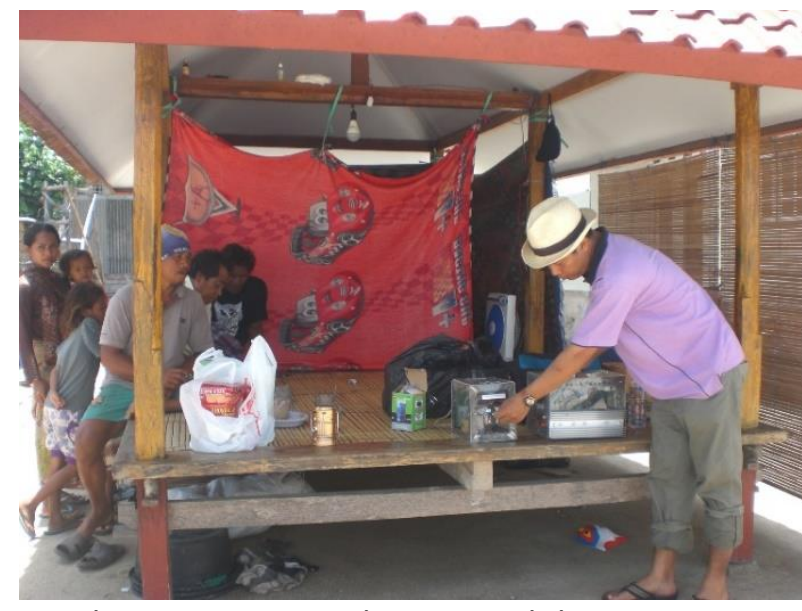

Gambar 2. Tim memberi penyuluhan mengenai prinsip kerja catu daya mandiri bertenaga batere

Kegiatan selanjutnya adalah peragaan cara menggunakan alat tersebut agar nantinya mitra pelaksana dapat menggunakannya dengan aman dan nyaman. Dimulai dengan memperagakan cara menggunakan catu daya mandiri bertenaga batere dil. Kegiatan selanjutnya adalah tanya jawab antara mitra pelaksana dengan tim pelaksana mengenai cara penggunaan alat tersebut.

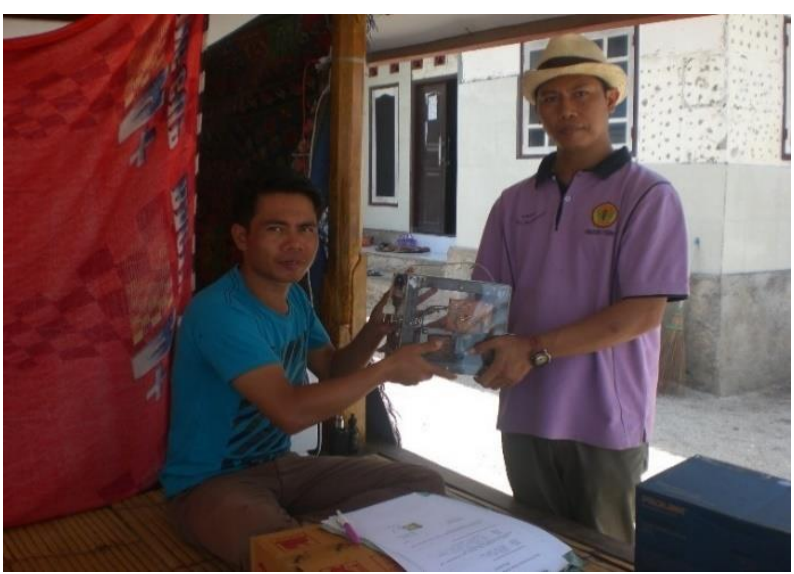

Gambar 3. Serah terima catu daya mandiri

Setelah mitra pelaksana dapat memahami prinsip kerja dan cara penggunaan peralatan tersebut dengan baik maka kegiatan selanjutnya adalah acara serah terima catu daya mandiri bertenaga batere untuk dapat digunakan di kantor desa. Dilanjutkan dengan pemasangan catu daya mandiri bertenaga batere di lokasi pemasangan yaitu di kantor desa untuk nantinya dapat digunakan untuk kepentingan kegiatan desa.

\section{Tahap evaluasi}

Untuk tahap terakhir yaitu evaluasi dilaksanakan dengan kunjungan lapangan untuk mengetahui hasil penggunaan catu daya mandiri bertenaga batere untuk beberapa waktu setelah peragaan cara penggunaan dan penyerahan peralatan. Selain itu juga wawancara kepada mitra mengenai penggunaan peralatan tersebut untuk mengetahui kesulitan penggunaan dan kekurangan yang mungkin masih dimiliki peralatan tersebut untuk perbaikan ke depan.

Diperoleh hasil evaluasi bahwa kegiatan pengabdian pada masyarakat ini telah memberikan beberapa manfaat kepada masyarakat terkait pengetahuan pemanfaatan teknologi untuk catu daya mandiri bertenaga batere. Dengan menggunakan catu daya mandiri bertenaga batere ini dapat menunjang kegiatan masyarakat yang membutuhkan layanan tenaga listrik pada saat dini hari sampai pagi hari, terutama bagi mereka yang aktivitas ekonominya atau pekerjaannya membutuhkan layanan tenaga listrik pada saatsaat tersebut sehingga dapat meningkatkan kinerja dan produktivitas mereka.

\section{KESIMPULAN DAN SARAN}

Kesimpulan yang dapat diambil dari kegiatan pengabdian kepada masyarakat kali ini adalah tim pelaksana yang beranggotakan staf pengajar Jurusan Teknik Elektro Fakultas Teknik Universitas Mataram telah melaksanakan kegiatan pengabdian kepada masyarakat di Desa Gili Gede Indah, Kecamatan Sekotong Tengah, Kabupaten Lombok Barat berupa penyuluhan mengenai prinsip kerja dan cara penggunaan catu daya listrik mandiri bertenaga batere kepada mitra pelaksana. Saran yang dapat diberikan dalam kegiatan pengabdian kepada masyarakat selanjutnya jumlah peralatan yang dihibahkan dapat lebih banyak lagi sehingga lebih banyak desa yang dapat dibantu.

\section{UCAPAN TERIMA KASIH}

Tim penulis menyampaikan terima kasih kepada LPPM Unram dan warga Desa Gili Gede Indah, Kecamatan Sekotong Tengah, Kabupaten Lombok Barat.

\section{DAFTAR PUSTAKA}

Citarsa, I.B.F., dkk., 2016. Performance Analysis Of Cascaded H-Bridge Multilevel Inverter Using 
Mixed Switching Frequency With Various DcLink Voltages. Proc. Of ICET4SD Yogyakarta. IOP Conf. Series; Materials Science and Engineering 105 (2016)012003.

Direktorat Pendayagunaan Pulau-pulau Kecil, 2012. http://www.ppkkp3k.kkp.go.id/direktoripulau/index.php/pu blic_c/pulau_info/4897, diakses tanggal 27 April 2019

Luo F.L., Ye H., 2013. Advanced DC/AC Inverters: Applications in Renewable Energi, Power
Electronics, Electrical Engineering, Energi, And Nanotechnology. Taylor \& Francis.

Satiawan, I.N.W., dkk., 2015. Investigasi Sudut Penyalaan Inverter Multilevel dengan Struktur Cascaded H-bridge untuk Sistem PLTS. Jurnal Dielektrika Vol. 2 No. 2, pp. 81 90.

Satiawan, I.N.W., dkk, 2017. Realisasi Inverter Multilevel Cascaded $\mathrm{H}$-Bridge (Chb) 5 Tingkat Satu Fasa Menggunakan Arduino Mega 2560, Jurnal Dielektrika Vol. 4 No. 2, pp. 127 -134 . 